\title{
Quality Evaluation of Policosanol Film-Coated Tablets by Simultaneous Determination of Eight Ingredients Using GC-FID and GC-MS
}

\author{
Han Yao ${ }^{1,2}$, Chunmin Wei ${ }^{2}$, Haibo Song ${ }^{2}$, Ruichen Guo ${ }^{2 *}$ \\ ${ }^{1}$ School of Pharmacy, Shandong University, Jinan, China; ${ }^{2}$ Institute of Clinical Pharmacology, Qilu Hospital of Shandong University, \\ Jinan, China. \\ Email: *grc7636@126.com
}

Received November $21^{\text {st }}, 2011$; revised December $27^{\text {th }}, 2011$; accepted January $7^{\text {th }}, 2012$

\begin{abstract}
A new and simple gas chromatographic (GC) method using flame ionization detector (FID) and mass spectrometry (MS) for the simultaneous determination of eight fatty alcohols in $10 \mathrm{mg}$ policosanol film-coated tablets was established and applied to the quality control (QC) of policosanol film-coated tablets. A DB-35MS capillary column $(30 \mathrm{~m} \times 0.32 \mathrm{~mm}$, $0.25 \mathrm{um}$ ) was employed for the separation. GC-FID was used to quantitatively analyze the eight ingredients with 1-eicosanol as internal standard, three of which were identified using GC-MS due to the lack of standard. The linearity, accuracy, precision, stability, robustness and sensitivity within the detection limits were evaluated. The average recovery of the method was $96.3 \%-100.4 \%$ and linearity was $(\mathrm{R}>0.999)$. The average drug content was found to be $96.8 \%$ of the labeled amount (10 mg).
\end{abstract}

Keywords: Policosanol; Fatty Alcohols; Gas Chromatography-Mass Spectrometry; Gas Chromatography-Hydrogen Flame Ionization Detector

\section{Introduction}

Policosanol is a mixture of eight long-chain aliphatic primary alcohols, 1-tetracosanol, 1-hexacosanol, 1-heptacosanol, 1-octacosanol, 1-nonacosanol, 1-triacontanol, 1dotriacontanol, and 1-tetratriacontanol originally isolated and purified from sugar cane (Saccharum officinarum L.) wax [1]. GC-FID has been frequently used for policosanol quantitation after derivatization with N-methylN-trimethylsilyltri-oroacetamide (MSTFA) as silylation reagent [2-5] which was laborious and time-consuming, and the reaction yield was multifactor affected. Nonderivatization GC methods were developed for policosanol analysis [6,7], but there has been no nonderivatization method reported for QC of these eight ingredients in policosanol film-coated tablets [8]. The method for the determination of five ingredients in policosanol film-coated tablets has been reported [9], 1-nonacosanol, 1-dotriacontanol and 1-tetratriacontanol in policosanol filmcoated tablets were not quantitatively analyzed due to the lack of standard. In the present work, 1-nonacosanol, 1-dotriacontanol and 1-tetratriacontanol were qualitatively analyzed by GC-MS. 1-octacosanol was used as reference preparation to quantity 1-nonacosanol, while

*Corresponding author. the correction factor of 1-triacontanol was used to quantity1-dotriacontanol and 1-tetratriacontanol. The developed method for simultaneous quantification of eight ingredients was sensitive, accurate, precise and reproducible and was applied to QC of $10 \mathrm{mg}$ policosanol filmcoated tablets.

\section{Experimental}

\subsection{Chemicals and Materials}

1-tetracosanol (98\%), 1-hexacosanol (97\%), 1-heptacosanol (98\%), 1-octacosanol (99\%), 1-triacontanol (99\%) and 1-eicosanol (97\%) were from Sigma-Aldrich. Chloroform was from J. T. Baker. Policosanol film-coated tablets (strength: $10 \mathrm{mg}$ ) were obtained from Zibo Shanchuan Pharmaceutical Factory (Shandong, China).

\subsection{Instrumentation}

GC studies were carried out on an Agilent 7890A gas chromatograph equipped with a FID detector (Agilent Technologies, G3461-6400, USA), a 5975C series MS and a 7683B series autosampler with a split/splitless injection port, operated in the splitless mode. GC separations were performed using a DB-35MS capillary column with 0.25 um film thickness $(30 \mathrm{~m} \times 0.32 \mathrm{~mm}$, USA). 
The GC was controlled by a computer running Chemstation software (Agilent Technologies, B.04.02).

\subsection{Chromatographic Conditions}

The column oven temperature was programmed from $200^{\circ} \mathrm{C}$ (held for $1 \mathrm{~min}$ ) to $270^{\circ} \mathrm{C}$ (held for $2 \mathrm{~min}$ ) at a rate of $8^{\circ} \mathrm{C} / \mathrm{min}$, then from $270^{\circ} \mathrm{C}$ to $310^{\circ} \mathrm{C}$ (held for $8 \mathrm{~min}$ ) at a rate of $20^{\circ} \mathrm{C} / \mathrm{min}$. The injector and detector temperature were set at $320^{\circ} \mathrm{C}$ and $340^{\circ} \mathrm{C}$, respectively. The carrier gas for FID was helium with a flow rate of $8 \mathrm{~mL} / \mathrm{min}$. The nitrogen and hydrogen flow rates were fixed at 42 and 50 $\mathrm{mL} / \mathrm{min}$ for FID detection respectively. Injection volume was $1 \mu \mathrm{L}$ at the splitless mode. The carrier gas for MS was helium and two microliter solution was injected in the splitless mode. The EI ion source was operated at $200^{\circ} \mathrm{C}$ with ionization voltage of $70 \mathrm{eV}$. The transfer line temperature was $250^{\circ} \mathrm{C}$. The emission current was $1.2 \mathrm{~A}$. Mass scan mode with $\mathrm{m} / \mathrm{z}$ of 20 to 500 was conducted.

\subsection{Preparation of Stock and Standard Solutions}

Internal standard working solution was prepared by accurately weighing $10 \mathrm{mg}$ of 1-eicosanol (97\%) dissolved with $100 \mathrm{~mL}$ of chloroform and then diluted to $10 \mu \mathrm{g} \cdot \mathrm{mL}^{-1}$ solution.

10 milligrams of 1-tetracosanol (98\%), $18 \mathrm{mg}$ of 1-hexacosanol (97\%), $10 \mathrm{mg}$ of 1-heptacosanol (98\%), $182 \mathrm{mg}$ of 1-octacosanol (99\%) and $34 \mathrm{mg}$ 1-triacontanol (97\%) were rigorously weighed and dissolved with chloroform in $250 \mathrm{~mL}$ volumetric flask. The concentration of each ingredient was $40,72,40,728$ and $136 \mu \mathrm{g} \cdot \mathrm{mL}^{-1}$, respectively.
Mixed working solution was prepared, mixed with internal standard working solution and dissolved with chloroform in $50 \mathrm{~mL}$ volumetric flask to obtain $3.2,5.76$, $3.2,58.24$ and $10.88 \mu \mathrm{g} \cdot \mathrm{mL}^{-1}$ of 1-tetracosanol, 1-hexacosanol, 1-heptacosanol, 1-octacosanol and 1-triacontanol. The concentration of total five alcohols was 81.28 $\mu \mathrm{g} \cdot \mathrm{mL}^{-1}$ and the concentration of IS was $1 \mu \mathrm{g} \cdot \mathrm{mL}^{-1}$.

\subsection{Sample Preparation}

Ten policosanol film-coated tablets (strength: $10 \mathrm{mg}$ ) were weighed and finely powdered. The average weight of tablets was determined with the weight of 10 tablets. A portion of powder $(78.4 \mathrm{mg})$ equivalent to the weight of four tenths tablet was accurately weighed into a 100 $\mathrm{mL}$ beaker flask with cover. Followed by $50 \mathrm{ml}$ internal standard working solution added, it was sonicated for 20 $\min$ at $60^{\circ} \mathrm{C}$ to obtain complete dissolution of the compounds and then the solution was filtered through a piece of filter paper. One microliter solution was injected into GC column for analysis, finally the amounts of the drug were calculated.

\section{Results and Discussion}

\subsection{Chromatographic Conditions}

The total ion current (TIC) chromatogram of film-coated tablet solution is shown in Figure 1. Usually, it is difficult to obtain the molecular ions $[\mathrm{M}]+$ of aliphatic primary alcohols by EI ionization, especially those with high molecular weight which are too active to give [M]+ EI ionization. However, some typical fragments such as

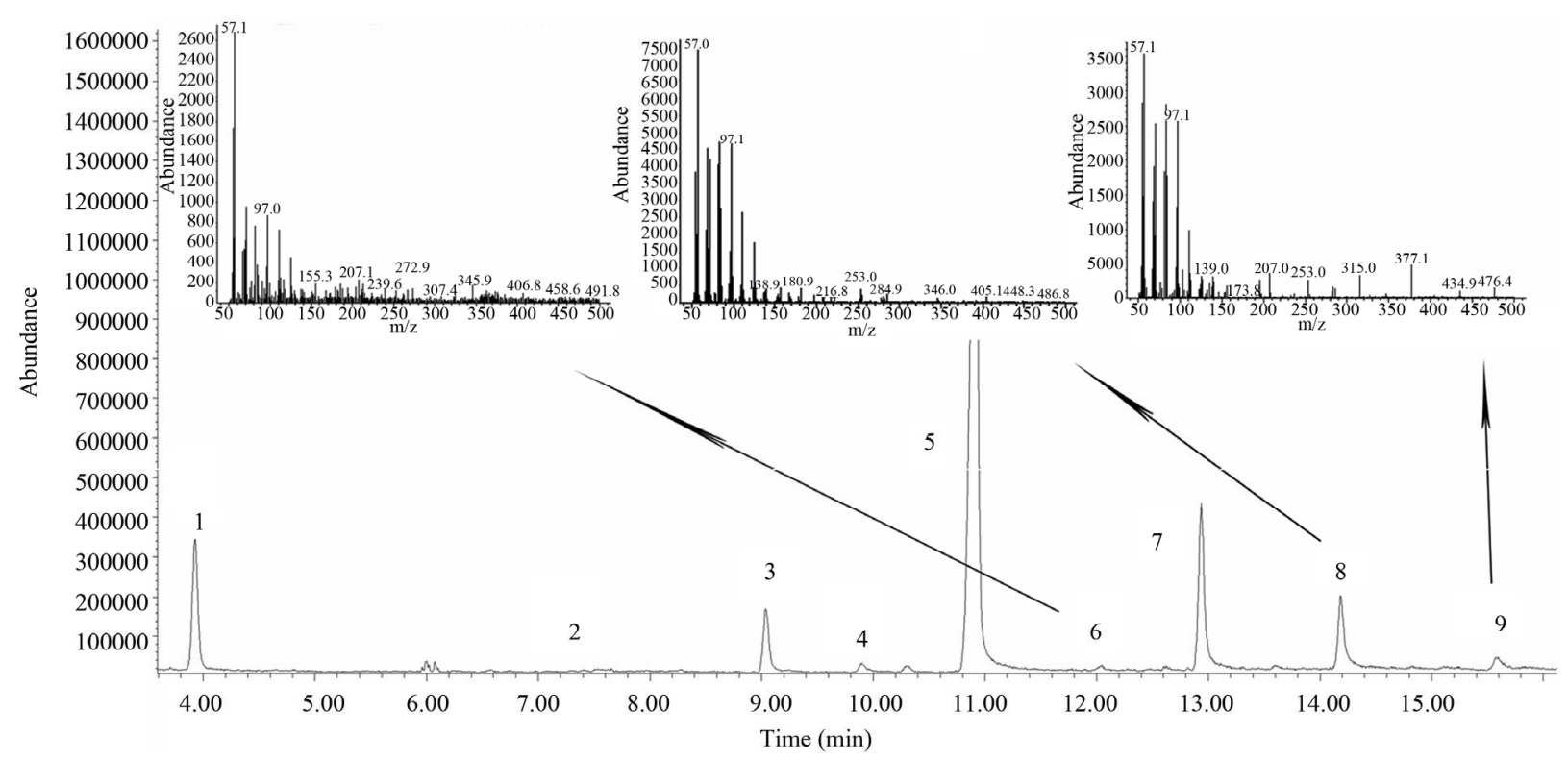

Figure 1. Total ion current chromatogram of film-coated tablet solution 1: Internal standard, 2: 1-tetracosanol, 3: 1-hexacosanol, 4: 1-heptacosanol, 5: 1-octacosanol, 6: 1-nonacosanol, 7: 1-triacontanol, 8: 1-duotriacontanol, 9: 1-tetratriacontanol and mass spectra of 1-triacontanol, 1-duotriacontanol and 1-tetratriacontanol. 
[M-18]+ were produced by lossing a water molecule through rearrangement. The mass spectrum of 1-nonacosanol, 1-duotriacontanol and 1-tetratriacontanol were shown in Figure 1. Serial Fragment ions such as $m / z$ 29, $43,57,83,97,111,125,139,153$ and 181 feature the long-chain hydrocarbon compounds. 1-nonacosanol, 1-duotriacontanol and 1-tetratriacontanol were eluted at 12.1, 14.2 and 15.5 min under this GC condition, the qualification characteristics of the three ingredients were listed in Table 1. The retention times of 1-triacontanol, 1-duotriacontanol and 1-tetratriacontanol in TIC chromatogram are the same as that in the GC-FID chromatogram in Figure 2. 1-octacosanol was used as reference preparation to quantity 1-nonacosanol, while the correction factor of 1-triacontanol was used to quantity1-dotriacontanol and 1-tetratriacontanol.

\subsection{Limit of Detection and Limit of Quantification}

The limit of detection and quantitation (LOD and LOQ) were definited at a signal-to-noise ratio of 3 and 10 as criteria. The LOQ and LOD values for each ingredient are summarized in Table 2.

\subsection{Linearity}

Linearity was assessed over the concentration range of $60.96-142.24 \mu \mathrm{g} \cdot \mathrm{mL}^{-1}$ of the mixed working solution. Calibration curves of five independent ingredients were constructed by plotting the ratio peak area of internal standard versus its respective concentration. The equations of linear regressions and regression coefficients of the calibration curve for the five ingredients are presented in Table 2.

\subsection{Precision}

The precision was investigated with repeatability (intra-day) and intermediate precision (inter-day). Repeatability was evaluated by injections of six sample of the mixed working solution per day, while the intermediate precision was performed over 3 days. The RSD of intra-day and inter-day study varied from $0.20 \%-0.85 \%$ and $0.59 \%-1.12 \%$, showed that the repeatability and intermediate precision of this method were satisfactory.

\subsection{Accuracy}

Three levels of the five ingredients were analyzed to evaluate the interference of adjuvants in tablets. The analytical recovery experiments were performed by adding known amounts of drug powder to mixed working solution. The recovery was calculated by original, spiked and found qualities as following listed in Table 3.

$$
\begin{aligned}
\text { Recovery }(\%) \\
=(\text { amount found }- \text { amount original }) / \text { amount spiked } \\
\quad \times 100
\end{aligned}
$$

\subsection{Stability}

To evaluate the stability of policosanol, film-coated tablet solutions were analyzed after being stored at room temperature for $0,1,2,3,5,7 \mathrm{~h}$. The RSD values of the eight alcohols were less than $2.93 \%$.

Table 1. Assignment of 1-nonacosanol, 1-duotriacontanol and 1-tetratriacontanol in TIC Chromatogram.

\begin{tabular}{cccc}
\hline $\begin{array}{c}\text { retention time } \\
(\mathrm{min})\end{array}$ & $\mathrm{m} / \mathrm{z}$ & compound & $\mathrm{MW}$ \\
\hline 12.1 & 97,406 & 1-nonacosanol & 424 \\
14.2 & 97,448 & 1-duotriacontanol & 466 \\
15.5 & 97,476 & 1-tetratriacontanol & 494 \\
\hline
\end{tabular}

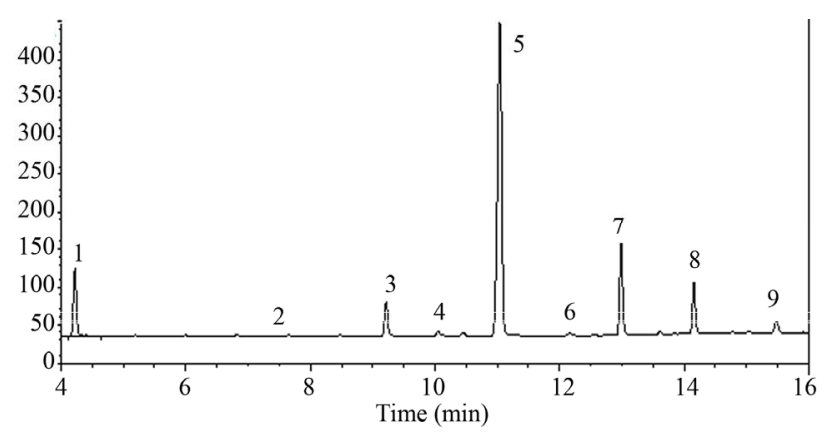

Figure 2. GC-FID chromatogram of film-coated tablet solution 1: Internal standard, 2: 1-tetracosanol (retention time, 7.6 min), 3: 1-hexacosanol (9.3 min), 4: 1-heptacosanol (10.1 min), 5: 1-octacosanol (11.1 min), 6: 1-nonacosanol (12.1 min), 7: 1-triacontanol (13.0 min), 8: 1-duotriacontanol

\begin{tabular}{|c|c|c|c|c|c|}
\hline Analytes & Linear regression data regression equation $\mathrm{A}$ & $\mathrm{R}$ & Linear range $(\mu \mathrm{g})$ & LOD (ng) & LOQ (ng) \\
\hline 1-tetracosanol & $y=30503.7844 x-96.009712$ & 0.99999 & $1.92-4.48$ & 120 & 40 \\
\hline 1-hexacosanol & $y=31274.6273 x-23.993823$ & 0.99954 & $3.456-8.064$ & 150 & 50 \\
\hline 1-heptacosanol & $y=31743.1676 x-12.393385$ & 0.99978 & $1.92-4.48$ & 80 & 26.7 \\
\hline 1-octacosanol & $y=30064.6069 x-195.8074$ & 0.99990 & $34.944-81.536$ & 169 & 56.4 \\
\hline 1-triacontanol & $y=28801.3458 x-41.961777$ & 0.99991 & $6.528-1.5232$ & 105 & 34.9 \\
\hline
\end{tabular}
(14.2 min), 9: 1-tetratriacontanol (15.5 min).

Table 2. Linear regression data, LOD and LOQ of five ingredients. 
Table 3. Recoveries of the five ingredients in $10 \mathrm{mg}$ policosanol film-coated tablets (mean $\pm \mathrm{sd}, \mathbf{n}=\mathbf{3}$ ).

\begin{tabular}{|c|c|c|c|c|c|}
\hline Analytes & Original $(\mu \mathrm{g})$ & Spiked $(\mu \mathrm{g})$ & Found $(\mu \mathrm{g})$ & Recovery (\%) & RSD (\%) \\
\hline \multirow{3}{*}{ 1-tetracosanol } & \multirow{3}{*}{4.27} & 128.0 & $132.1 \pm 0.96$ & $99.9 \pm 0.0075$ & 0.75 \\
\hline & & 160.0 & $163.5 \pm 2.26$ & $99.5 \pm 0.0158$ & 1.59 \\
\hline & & 192.0 & $193.4 \pm 3.04$ & $98.5 \pm 0.0197$ & 2.00 \\
\hline \multirow{3}{*}{ 1-hexacosanol } & \multirow{3}{*}{211.7} & 230.4 & $441.9 \pm 1.84$ & $99.9 \pm 0.0080$ & 0.80 \\
\hline & & 288.0 & $498.5 \pm 2.90$ & $99.6 \pm 0.0135$ & 1.36 \\
\hline & & 345.6 & $551.8 \pm 3.46$ & $98.4 \pm 0.0183$ & 1.86 \\
\hline \multirow{3}{*}{ 1-heptacosanol } & \multirow{3}{*}{41.0} & 128.0 & $164.3 \pm 0.58$ & $96.3 \pm 0.0140$ & 1.45 \\
\hline & & 160.0 & $201.6 \pm 1.03$ & $100.4 \pm 0.0123$ & 1.23 \\
\hline & & 192.0 & $231.1 \pm 1.66$ & $99.0 \pm 0.0166$ & 1.67 \\
\hline \multirow{3}{*}{ 1-octacosanol } & \multirow{3}{*}{2595.5} & 2329.6 & $4894.8 \pm 11.1$ & $98.7 \pm 0.0048$ & 0.48 \\
\hline & & 2912.0 & $5487.1 \pm 24.6$ & $99.3 \pm 0.0156$ & 1.57 \\
\hline & & 3494.4 & $6034.0 \pm 41.3$ & $98.4 \pm 0.0180$ & 1.83 \\
\hline \multirow{3}{*}{ 1-triacontanol } & \multirow{3}{*}{574.1} & 435.2 & $998.0 \pm 1.18$ & $97.4 \pm 0.0027$ & 0.28 \\
\hline & & 544.0 & $1114.8 \pm 5.23$ & $99.4 \pm 0.0183$ & 1.84 \\
\hline & & 652.8 & $1225.6 \pm 8.66$ & $99.8 \pm 0.0117$ & 1.18 \\
\hline
\end{tabular}

Table 4. Factors and resolutions investigated in the robustness study.

\begin{tabular}{|c|c|c|c|}
\hline Factor & Variation & $\mathrm{R}_{1}^{\mathrm{A}}$ & $\mathrm{R}_{2}^{\mathrm{B}}$ \\
\hline Temperature of injector, ${ }^{\circ} \mathrm{C}$ & $320-10$ & $>3.9$ & $>2.4$ \\
\hline Temperature of detector, ${ }^{\circ} \mathrm{C}$ & $340-10$ & $>4.0$ & $>2.3$ \\
\hline Flow rate, $\mathrm{mL} / \mathrm{min}$ & $8 \pm 0.5$ & $>4.4$ & $>2.2$ \\
\hline Temperature rate, ${ }^{\circ} \mathrm{C} / \mathrm{min}$ & $8 \pm 2,20 \pm 2$ & $>3.8$ & $>2.2$ \\
\hline Initial oven temperature, ${ }^{\circ} \mathrm{C}$ & $200 \pm 5$ & $>3.9$ & $>2.3$ \\
\hline Terminal oven temperature, ${ }^{\circ} \mathrm{C}$ & $320 \pm 5$ & $>4.0$ & $>2.4$ \\
\hline
\end{tabular}

${ }^{\mathrm{A}}$ Resolution of ingredients in mixed working solution; ${ }^{\mathrm{B}}$ Resolution of ingredients in film-coated tablet solution.

Table 5. Application of GC-MS and GC-FID method for the determination of policosanol tablets $(\mathrm{mean} \pm \mathrm{SD}, \mathbf{n}=\mathbf{1 0})$.

\begin{tabular}{|c|c|c|c|c|}
\hline Analytes & Nominal (mg) & Found (mg) & Contents $(\%)$ & RSD (\%) \\
\hline 1-tetracosanol & $0.001-0.2$ & $0.00996 \pm 0.000281$ & $0.0996 \pm 0.00281$ & 2.82 \\
\hline 1- hexacosanol & $0.3-1.0$ & $0.526 \pm 0.0051$ & $5.26 \pm 0.051$ & 0.969 \\
\hline 1-heptacosanol & $0.01-0.3$ & $0.102 \pm 0.00313$ & $1.02 \pm 0.0313$ & 3.07 \\
\hline 1-octacosanol & $6.0-7.0$ & $6.53 \pm 0.0211$ & $65.3 \pm 0.211$ & 0.323 \\
\hline 1-nonacosanol & $0.01-0.2$ & $0.0185 \pm 0.000578$ & $0.185 \pm 0.00578$ & 3.12 \\
\hline 1-triacontanol & $1.0-1.5$ & $1.45 \pm 0.00922$ & $14.5 \pm 0.0922$ & 0.636 \\
\hline 1-duotriacontanol & $0.5-1.0$ & $0.774 \pm 0.0206$ & $7.74 \pm 0.206$ & 2.66 \\
\hline 1-tetratriacontanol & $0.01-0.5$ & $0.265 \pm 0.0104$ & $2.65 \pm 0.104$ & 3.92 \\
\hline Total alcohols & 10 & $9.68 \pm 0.0463$ & $96.8 \pm 0.463$ & 0.478 \\
\hline
\end{tabular}

\subsection{Robustness}

To assess robustness, the experimental conditions were deliberately altered, and resolution between the adjacent alcohols of mixed working solution and film-coated tablet solution were evaluated. Six variables (flow rate, detector temperature, injector temperature, initial oven temperature and terminal oven temperature) were studied by performing 10 separate experiments of both mixed standard solution $(\mathrm{n}=6)$ and sample solutions $(\mathrm{n}=6)$.
The selected operating conditions are shown in Table 4. In all the deliberate varied chromatographic conditions, the resolution between two adjacent alcohols of mixed working solution was greater than 3.8, while the resolution between two adjacent alcohols of film-coated tablet solutions was greater than 2.2.

\subsection{Quality Control}

The developed method was applied to the determination 
of $10 \mathrm{mg}$ policosanol film-coated tablets $(\mathrm{n}=10)$. The QC results were showed in Table 5. The average drug content was found to be $96.8 \%$ of the labeled amount (10 $\mathrm{mg})$.

\section{Results and Discussion}

A sensitive and accurate GC method has developed, validated used for quantitative determination of eight ingredients in $10 \mathrm{mg}$ film-coated policosanol tablets. The method is simple and specific, as all peaks are well separated. Symmetry factors of both eight peaks are all between 0.8 and 1.2 which can ensure the requirement for survey accuracy. Therefore, the proposed method can be used for the routine QC analysis of simultaneous determination of eight ingredients.

\section{REFERENCES}

[1] S. Irmak, N. T. Dunford and J. Milligan, "Policosanol Contents of Beeswax, Sugar Cane and Wheat Extracts," Food Chemistry, Vol. 95, No. 2, 2006, pp. 312-318. doi:10.1016/j.foodchem.2005.01.009

[2] S. Irmak and N. T. Dunford, "Policosanol Contents and Compositions of Wheat Varieties," Journal of Agricultural and Food Chemistry, Vol. 53, No. 14, 2005, pp. 5583-5586. doi:10.1021/jf050508r
[3] J. C. Taylor, L. Rapport and G. B. Lockwood, "Octacosanol in Human Health," Nutrition, Vol. 19, No. 2, 2003 , pp. 192-195. doi:10.1016/S0899-9007(02)00869-9

[4] S. K. Ries, V. Wert, C. C. Sweeley and R. A. Leavitt, "Triacontanol: A New Naturally Occurring Plant Growth Regulator," Science, Vol. 195, No. 4284, 1977, pp. 13391341. doi:10.1126/science.195.4284.1339

[5] B. Liu and X. Su, "Chemical Constituents Analysis of Policosanol by GC and GC/MS," Chinese Journal of Chromatography, Vol. 24, No. 2, 2006, p. 211.

[6] J. Lu, W. B. Zhao, N. Zang, J. F. Li, M. Zhang and Y. Wang, "Determination of Policosanol by Gas Chromatography," Science and Technology of Food Industry, Vol. 25, No. 7, 2004, pp. 129-131.

[7] H. G. Lu, Z. L. Gao and Q. Z. Guo, "Analytical Method of Qualitative and Quantitative Analysis of n-Triacontanol," Chemical Industry Times, Vol. 24, No. 4, 2002, pp. 29-31.

[8] R. Sierra, V. L. Gonzalez and J. Magraner, "Validation of a Gas Chromatographic Method for Determination of Fatty Alcohols in $10 \mathrm{mg}$ Film-Coated Tablets of Policosanol," Journal of AOAC International, Vol. 85, No. 3, 2002, pp. 563-566.

[9] M. L. Huang, G. F. Jiang and G. F. Lei, "GC Determination of Five Main Ingredients in Policosanol Tablets," Chinese Journal of Pharmaceutical Analysis, Vol. 27, No. 8, 2007, pp. 1168-1171. 